\title{
Photo-assisted recall increases estimates of energy and macronutrient intake in adults with intellectual and developmental disabilities
}

\author{
Lauren T. Ptomey, PhD, RD, LD, \\ Postdoctoral Fellow, Cardiovascular Research Institute, Division of Internal Medicine, University \\ of Kansas Medical Center, 3901 Rainbow Boulevard; MS 4013; Kansas City, KS 66160, Phone \\ Number: 913-945-8182, Fax Number: 913-588-8946
}

\section{Stephen D. Herrmann, PhD, \\ Postdoctoral Fellow, Cardiovascular Research Institute, Division of Internal Medicine, University of Kansas Medical Center, 1301 Sunnyside Ave; Robinson Room 100; Lawrence, KS 66045, Phone Number: 785-864-0776, Fax Number: 785-864-2009}

\section{Jaehoon Lee, PhD,}

Research Associate, 1425 Jayhawk Boulevard; Lawrence, KS 66045-7547, Center for Research Methods and Data Analysis, University of Kansas, Lawrence, KS 66045, Phone Number: 785-550-7098, Fax Number: 785-864-2009

Debra K. Sullivan, PhD, RD, Department Chair and Professor - Dietetics and Nutrition, Department of Dietetics and Nutrition, University of Kansas Medical Center, 3901 Rainbow Boulevard; MS 4013; Kansas City, KS 66160, Phone Number: 913-588-5357, Fax Number: 913-588-8946

Mary F. Rondon, MS, RD, LD, and

Research Assistant, Cardiovascular Research Institute, Division of Internal Medicine, University of Kansas Medical Center, 1301 Sunnyside Ave; Robinson Room 100; Lawrence, KS 66045, Phone Number: 785-864-0782, Fax Number: 785-864-2009

\section{Joseph E. Donnelly, EdD, FACSM}

Professor-Department of Internal Medicine, Cardiovascular Research Institute, Director-Center for Physical Activity and Weight Management, University of Kansas Medical Center, 1301 Sunnyside Ave; Robinson Room 100; Lawrence, KS 66045, Phone Number: 785-864-0797, Fax Number: 785-864-2009

Lauren T. Ptomey: Lptomey@kumc.edu; Stephen D. Herrmann: sherrmann@ku.edu; Jaehoon Lee: jaehoon@ku.edu; Debra K. Sullivan: dsulliva@kumc.edu; Mary F. Rondon: mrondon@ku.edu; Joseph E. Donnelly: jdonnelly@ku.edu

\section{Abstract}

Diet assessment of adults with intellectual and developmental disabilities (IDD) is challenging due to their limited cognitive abilities. The objective of this study was to examine the feasibility and outcomes of combining photos with 24-hour dietary recalls for the assessment of energy and macronutrient intake in adults with IDD. Participants used an iPad 2 tablet computer to take

\footnotetext{
(C) 2013 Academy of Nutrition and Dietetics. Published by Elsevier Inc. All rights reserved. Correspondence to: Lauren T. Ptomey, Lptomey@kumc . edu.

Publisher's Disclaimer: This is a PDF file of an unedited manuscript that has been accepted for publication. As a service to our customers we are providing this early version of the manuscript. The manuscript will undergo copyediting, typesetting, and review of the resulting proof before it is published in its final citable form. Please note that during the production process errors may be discovered which could affect the content, and all legal disclaimers that apply to the journal pertain.
} 
photos of all food and beverages consumed before a standard, multiple-pass, 24-hour dietary recall. Following the standard 24-hour diet recall, the photos were reviewed with the participant for clarification details (e.g., portion size, etc.) and differences were recorded. The standard 24hour recall and the photo-assisted recall were entered separately into Nutrition Data System for Research for computerized dietary analysis. Sixty-four eating occasions were entered from 23 participants (48\% female; mean age $26.4 \pm 9.7$ years). Participants captured photos for $66.5 \% \pm$ $30.4 \%$ of all recorded eating occasions. Greater energy intake per eating occasion was reported with the photo-assisted recalls than the standard recalls $(625.6 \pm 85.7 \mathrm{kcals}$ vs. $497.2 \pm 86.6 \mathrm{kcals}$, $p=0.002)$ and a greater intake of grams of fat $(p=0.006)$ protein $(p=0.029)$ and carbohydrates $(p=0.003)$. Photo-assisted 24-hour recalls provided a significant increase in total calories and macronutrient content compared to a standard 24-hour recall and may be a feasible method to enhance dietary assessment in adults with IDD.

\section{Keywords}

24-hour dietary recall; intellectual and developmental disabilities; photo-assisted dietary recall

\section{INTRODUCTION}

Adults with intellectual and developmental disabilities (IDD) are a population that may benefit from dietary monitoring. Individuals with IDD have an increased risk of heart disease, obesity, osteoporosis, seizures; as well as lower levels of fitness. ${ }^{1-4}$ Prevalence of obesity in adults with IDD is approximately two to three times greater than the general population. ${ }^{5-9}$

While the need for dietary assessment and monitoring is high in adults with IDD, there are inherent challenges in collecting dietary intakes data due to compromised cognitive functioning, poor memory, and a shortened attention span. ${ }^{10,11}$ Due to the significant barriers in collecting valid data, researchers have not yet validated a method for dietary assessment in adults with IDD. ${ }^{11}$

Twenty-four hour recalls are a commonly used method of dietary assessment. ${ }^{12-14}$ It balances reliability of responses with a fairly low respondent burden and avoids dietary intake changes in response to recording foods at the time they are eaten. ${ }^{12}$ However, there are no published validation studies in adults with IDD using 24-hour recalls, or any other dietary assessment method. Thus, while 24-hour recalls are a valid dietary assessment in the general population, they may not be suitable for use in adults with IDD. Dietary assessment methods previously used in adults with IDD include a Block Screening Questionnaire for Fat Intake and the Behavioral Risk Factor Surveillance System's Fruit and Vegetable Module, ${ }^{15}$ a food frequency questionnaire, ${ }^{10,16}$ and proxy-assisted 3-day food record. ${ }^{17,18}$. However, the accuracy of the data is a commonly reported limitation as these assessment methods have not been validated for this population. ${ }^{10,15,17,18}$

A photo-assisted food recall is a new technique in which digital images are taken of all food and beverages consumed during the recall period. This method has been validated by comparing the images with a direct observation using the weighed and measured technique. Photo-assisted food recalls have been validated for assessing portion sizes, ${ }^{19}$ and assessing energy and macronutrient intake in subjects eating prepared meals, ${ }^{20-23}$ home meals, ${ }^{24-26}$ and in confined settings. ${ }^{27}$ The results indicate that photo-assisted recalls are useful in assessing dietary intake in the general population.

Elinder et al. ${ }^{28}$ conducted a feasibility study in a population of adults with IDD ( $\mathrm{n}=18$; ages 23-60 years) to investigate participants' ability to use cameras to take accurate images of 
food. It was found that with reminders from staff, participants with IDD photographed $85 \%$ of all observed eating or drinking occasions. The correlations between items assessed in images and direct observations were strong. The researchers concluded that personal digital photography appears to be a feasible and reliable method for assessing dietary intake in individuals with IDD. Humphries, Traci, and Seekins ${ }^{29}$ conducted photo-assisted 24-hour recalls in nine adults with IDD to determine if photo-assisted recalls would result in more food items being collected. The researchers determined that the photo-assisted food recall may allow more food items to be identified; however, the extent to how much more was eaten in terms of total energy and macronutrient intake was not reported and remains unknown.

While previous studies suggest that using photos to enhance recall methods may improve the quantification of food and beverage intake in adults with IDD, no information is available regarding the utility of photo-assisted recalls to improve the measurement of total energy and macronutrient intake for individuals with IDD. As individuals with IDD are at an increased risk of obesity and related health complications, ${ }^{30-32}$ improving the methods to obtain accurate dietary assessment methods, especially estimates of energy and macronutrient intake, may help to design the necessary diets for weight loss and health promotion. Therefore, the aim of this study was to determine if the use of photo-assisted recalls significantly improves the estimated amount of energy and macronutrient intake reported in 24-hour dietary recalls, in adults with IDD.

\section{METHODS}

This was a cross-sectional design study in 23 adults with IDD (Age $=26.4 \pm 9.7$ years; $\left.\mathrm{BMI}=35.5 \pm 5.7 \mathrm{~kg} / \mathrm{m}^{2}\right)$. Table 1 presents total demographic data. All participants were community dwelling adults ( $\geq 18$ years of age) with mild to moderate IDD enrolled in an ongoing healthy lifestyle intervention trial. Participant's level of IDD impairment (mild vs. moderate) had been previously assessed by The Community Developmental Disability Organization of Kansas. For this study, mild IDD was defined as having few activities of daily living that required direct assistance and moderate IDD was defined as typically needing direct assistance for most activities as determined by participants' caretakers. To be included, participants needed to be able to communicate preferences (e.g., foods liked and disliked), wants (e.g., more to eat, drink), and needs (e.g., assistance with food preparation) through spoken language, sign language, or augmentative and alternative communication systems, such as voice output communication aides. Participants were recruited through local community programs and agencies. Each participant and their legal guardian (if applicable) signed a consent form approved by the University of Kansas institutional review board.

The iPad 2 (Apple, Cupertino, CA, USA), Wi-Fi only model $(241.2 \times 185.7 \times 8.8 \mathrm{~mm} ; 601$ g) with a 246-mm screen (diagonal dimension), 16 GB storage and iOS5 operating system was used for this study. ${ }^{33}$ The iPad 2 uses a LED backlight screen with a $1024 \times 768$ screen resolution at 132 pixels per inch and battery life of up to 10 hours. The iPad 2's rear-facing camera (1280 $\times 720$ pixels or 0.92 megapixel camera with autofocus) was used for the photo-assisted recalls. Study personnel delivered the tablet to participants approximately two days before the scheduled 24-hour hour recall (visit one). During this 30-minute visit, the participant was instructed on basic tablet computer functions. Specifically, the study personnel demonstrated how to operate the camera application and observed the participant independently take satisfactory photos. Participants were instructed to take before and after photos with the tablet computer of all food and beverages consumed 24-hours prior to the dietary assessment. Each participant was given a fiduciary marker (a $5 \mathrm{~cm} \times 5 \mathrm{~cm}$ checked square) to be included in all photos to serve as a reference measure to aid study staff in 
determining portion sizes. Calendar prompts were programmed into the tablet computer to remind participants to comply with the photo/recall protocol.

During the home visit (visit two) a registered dietitian, who had passed internal reliability checks against multiple registered dietitians to conduct 24-hour recalls in this population, conducted a 24-hour multiple pass dietary recall. The recall followed the USDA multiple pass method consisting of 5 steps: (a) the quick list, which is an uninterrupted listing by the subject of foods and beverages consumed; (b) the forgotten foods list, which queries the subject on categories of foods that have been documented as frequently forgotten; (c) a time and occasion at which foods were consumed; (d) the detail cycle, which elicits descriptions of foods and amounts eaten aided by the interactive use of measuring guides; and finally (e) the final probe review. ${ }^{13,34,35}$ The portion guides used in the interviews were 3-dimensional models consisting of a variety of items intended to provide a reference and improve recall accuracy (i.e., glasses, mugs, bowls, circles, thickness sticks, chip bags, drink bottles, a 12inch ruler, measuring cups and spoons, a grid, wedges, geometric shapes, and diagrams of chicken pieces). ${ }^{36}$ After completing the multiple pass 24 -hour recall, the date and time stamped photos were evaluated. Each photographed meal or food item was discussed with the participant to identify if the photos provided additional detail regarding the food type, portion size, and other characteristics (e.g., drinks, side dishes, ingredients, condiments, etc.). The registered dietitian made a note by each meal recorded to identify if a photo had been taken of that meal. Food items, portion size, and specific details about any food items that were different from the standard recall, were recorded in a designated column on the 24hour recall form to distinguish the photo-assisted recall from the standard recall. Additional details, including the reasons for the differences (e.g., forgot food, inaccurate portion size), number of meals captured by photo, and total number of meals consumed were also recorded.

The registered dietitian, who initially collected the recalls, entered all dietary records into Nutrition Data System for Research (NDSR) software version 2011. ${ }^{37,38}$ The standard and the photo-assisted recalls were entered as two separate records. All photos were uploaded to a secure server and available to the registered dietitian while entering the photo assisted recall into NDSR. Dietary analysis of the recalls was exported from NDSR to determine intake of total calories, grams of fat, carbohydrate, and protein.

Mixed modeling for repeated measures ${ }^{39-41}$ was used to examine the differences between the standard recall and the photo-assisted recall. Models were adjusted for the participants' age, gender, race, education level, and level of IDD impairment (mild vs. moderate). ${ }^{42} \mathrm{~A}$ priori power calculation ${ }^{43}$ with pilot data indicated that a minimal sample size of 18 participants would provide adequate power to detect differences in energy and macronutrient data between the standard and photo-assisted 24-hour recalls (power $=0.80$ with $n=18$ and $d=0.64)$. Statistical significance was determined at 0.05 alpha level and all analyses were conducted using Statistical Analysis Software (version 9.2, 2012, SAS Institute Inc). ${ }^{44}$

\section{RESULTS}

Sixty-four eating occasions were entered from 23 participants. Participants captured photos for $66.5 \pm 30.4 \%$ of all eating occasions. There was an average of $2.7 \pm 1.1$ dietary differences, such as incorrect portion size, between the standard and photo-assisted recall per meal captured by the tablet computer. The most common difference was forgetting a food eaten $(45.9 \%)$ followed by having incorrect or missing details about a food item (29.6\%), reporting an incorrect portion size (21.4\%), and reporting a food not actually consumed $(3.1 \%)$. 
Table 2 provides data describing the intake differences between standard and photo-assisted recalls for total energy and grams of fat, carbohydrate, protein. The photo-assisted 24-hour recalls reported significantly greater intakes of total calories (a 25.8\% increase) grams of fat (a $41.4 \%$ increase) carbohydrates (a $19.1 \%$ increase) and protein (a $23.0 \%$ increase) per eating occasion (all $\mathrm{p}<0.05$ ).

The macronutrient composition (percent of total energy from grams of fat, protein, and carbohydrates) was evaluated for both the standard and photo-assisted recall to examine whether certain types of foods were captured differently between methods (e.g., high fat foods were concealed, etc.). Figure 1 illustrates the macronutrient composition for both recall methods. There was no statistical difference for the percent distribution of grams of fat, protein, or carbohydrates.

\section{DISCUSSION}

This study was designed to determine if photo-assisted recalls provide added value when assessing 24-hour dietary recall in adults with IDD. The results of this study indicate that the use of photo-assisted 24-hour food recalls provided significantly greater intake of total calories and macronutrients compared to standard 24-hour food recalls. These significant differences in caloric and macronutrient intake may have important clinical implications when evaluating dietary intake in this population as these results suggest that standard 24hour food recalls alone may underestimate dietary intake in adults with IDD.

Similar to Elinder et al ${ }^{28}$ all participants in this study were able to take photos of their meals without assistance. In this study, with the calendar prompts from the tablet computer, participants were able to capture photos of two-thirds of all eating occasions. The most common reason for not taking a photo of a meal reported in the standard recall was due to consuming a meal while at work or at a public event where the participant felt uncomfortable bringing the tablet computer. The participants in this study ranged in age from 18-60 years, suggesting that both younger individuals who may have been more familiar with technology, such as a camera, computer, or tablet computer, and older individuals who may be less familiar with this technology were able to use the tablet computer to take photos of food.

This study identified a $25.8 \%$ greater energy intake when photos were used to assist the recall than without. The primary reason for the higher reported intake in photo-assisted recalls was that the photos captured a food or an entire meal that was forgotten in the standard recall, for example forgetting breadsticks with pasta or forgetting an entire afternoon snack. Another area where the photos provided an additional benefit was in improving the accuracy of portion size estimation, for example reporting 2 slices of pizza when a photo showed 4 slices of pizza, or a reporting a small beverage when the photo showed a large. Significantly, more grams of fat, carbohydrate, and protein intake were reported in the photo-assisted 24-hour recall compared to the standard 24-hour recall ( $p<$ 0.05 ); however, the macronutrient composition (percent calories from fat, protein, and carbohydrate) was not different. This shows that the participants were probably not intentionally misreporting certain types of foods (e.g., high fat foods) on the standard 24hour recall. However, it may indicate that the participants were unable to accurately recall all of the food/beverages consumed or the portion sizes.

While this study highlights the value of using photo-assisted 24-hour recalls in adults with IDD, several limitations do exist. Participants in this study were not randomly selected and were volunteers in a healthy lifestyle intervention, which may limit the generalizability of this study. It can also be suggested that the act of taking photos may help the participants 
have a better memory of what was eaten; however, Humphries et al (2008) found that the act of solely taking a photo did not improve dietary recalls in adults with IDD. ${ }^{29}$ Finally, not all meals were captured throughout the day, as participants did not bring the tablet computer to work. In turn, it was not possible to evaluate the difference in energy and macronutrient intake between recall methods for all eating occasions in the 24-hour period.

While photo-assisted 24-hour recalls appear to be a feasible method of collecting dietary intake information from adults with IDD, it is still not a validated dietary assessment method in this population. Methodology still needs to be developed to assure the capture of all meals consumed throughout the day. Furthermore, validation studies need to be conducted to determine if photo-assisted recalls, can be used to provide a valid dietary assessment data in adults with IDD. Common validation practices are to compare the dietary assessment method against another similar method, ${ }^{14}$ to compare the dietary assessment to direct observation of meal consumption, ${ }^{12}$ and the use of doubly labeled water. ${ }^{45-47}$ As no other validated dietary assessment exists in this population, comparing one dietary assessment method to another would not be feasible; thus, direct observation or the use of doubly labeled water would be the best techniques.

To our knowledge this is the first study to examine the difference in energy and macronutrient intake between standard and photo-assisted 24-hour hour recalls in adults with IDD. Although photos were not available for all meals, the photos provided substantial additional detail about dietary intake. This information may be valuable as individuals and clinicians working with adults with IDD may be able to use photo-assisted recalls to obtain more accurate dietary information that could allow for better assessments of nutritional intake and possibly help identify nutritional concerns and deficiencies in the individuals with whom they are working.

\section{SUMMARY}

Adults with IDD are a nutritionally vulnerable population but lack a valid dietary assessment technique. Photo-assisted 24-hour recalls provided a statistically significant improvement for estimation of total calories and macronutrient intake compared to a standard 24-hour recall in adults with IDD. The clinical implications of this study suggest that use of standard 24-hour food recalls alone may underestimate the dietary intake of adults with IDD. Nutrition professionals working with adults with IDD should be aware of the challenges in obtaining accurate dietary assessments, and be cognizant that underreporting may occur. This study provides evidence that photo-assisted 24-hour food recalls are a feasible dietary assessment method in adults with IDD that may improve estimates of dietary intake. However, validation studies are needed to determine if this method provides an accurate and reliable assessment of the dietary intake of adults with IDD.

\section{Acknowledgments}

Funding

Funding provided in part by 5R01DK83539 from the National Institute of Diabetes and Digestive and Kidney Diseases and Health Management Resources, Boston MA

The authors would like to acknowledge Jeffery Honas, Jessica Betts, and Muriel Saunders for their contributions to this project. 


\section{References}

1. Heller T, McCubbin JA, Drum C, Peterson J. Physical Activity and Nutrition Health Promotion Interventions: What Is Working for People with Intellectual Disabilities? Intellect Dev Disabil. Feb; 2011 49(1):26-36. [PubMed: 21338310]

2. He FJ, MacGregor GA. Effect of Longer-Term Modest Salt Reduction on Blood Pressure. Cochrane Database Syst Rev. 2004; (3):CD004937. [PubMed: 15266549]

3. Draheim CC, Williams DP, McCubbin JA. Physical Activity, Dietary Intake, and the Insulin Resistance Syndrome in Nondiabetic Adults with Mental Retardation. Am J Ment Retard. Sep; 2002 107(5):361-375. [PubMed: 12186577]

4. Draheim CC. Cardiovascular Disease Prevalence and Risk Factors of Persons with Mental Retardation. Ment Retard Dev Disabil Res Rev. 2006; 12(1):3-12. [PubMed: 16435328]

5. Rimmer JH, Braddock D, Marks B. Health Characteristics and Behaviors of Adults with Mental Retardation Residing in Three Living Arrangements. Res Dev Disabil. Nov-Dec;1995 16(6):489499. [PubMed: 8584768]

6. Rimmer JH, Wang E. Obesity Prevalence among a Group of Chicago Residents with Disabilities. Arch Phys Med Rehabil. Jul; 2005 86(7):1461-1464. [PubMed: 16003681]

7. Harris N, Rosenberg A, Jangda S, O'Brien K, Gallagher ML. Prevalence of Obesity in International Special Olympic Athletes as Determined by Body Mass Index. J Am Diet Assoc. Feb; 2003 103(2): 235-237. [PubMed: 12589332]

8. Yamaki K. Body Weight Status among Adults with Intellectual Disability in the Community. Ment Retard. Feb; 2005 43(1):1-10. [PubMed: 15628929]

9. Melville CA, Hamilton S, Hankey CR, Miller S, Boyle S. The Prevalence and Determinants of Obesity in Adults with Intellectual Disabilities. Obes Rev. May; 2007 8(3):223-230. [PubMed: 17444964]

10. Braunschweig CL, Gomez S, Sheean P, Tomey KM, Rimmer J, Heller T. Nutritional Status and Risk Factors for Chronic Disease in Urban-Dwelling Adults with Down Syndrome. Am J Ment Retard. Mar; 2004 109(2):186-193. [PubMed: 15000671]

11. Humphries K, Traci MA, Seekins T. Nutrition and Adults with Intellectual or Developmental Disabilities: Systematic Literature Review Results. Intellect Dev Disabil. Jun; 2009 47(3):163185. [PubMed: 19489663]

12. Gibson, R. Principles of Nutritional Assessment. 2. New York: Oxford University Press; 2005.

13. Conway JM, Ingwersen LA, Moshfegh AJ. Accuracy of Dietary Recall Using the Usda Five-Step Multiple-Pass Method in Men: An Observational Validation Study. J Am Diet Assoc. Apr; 2004 104(4):595-603. [PubMed: 15054345]

14. Guest C. Design Concepts in Nutritional Epidemiology. J Epidemiol Community Health. Jun.1992 46(3):317.

15. Draheim CC, Stanish HI, Williams DP, McCubbin JA. Dietary Intake of Adults with Mental Retardation Who Reside in Community Settings. Am J Ment Retard. Sep; 2007 112(5):392-400. [PubMed: 17676962]

16. Robertson J, Emerson E, Gregory N, et al. Lifestyle Related Risk Factors for Poor Health in Residential Settings for People with Intellectual Disabilities. Res Dev Disabil. Nov-Dec;2000 21(6):469-486. [PubMed: 11153830]

17. Adolfsson P, Sydner YM, Fjellstrom C, Lewin B, Andersson A. Observed Dietary Intake in Adults with Intellectual Disability Living in the Community. Food Nutr Res. 2008:52.

18. Saunders RR, Saunders MD, Donnelly JE, et al. Evaluation of an Approach to Weight Loss in Adults with Intellectual or Developmental Disabilities. Intellect Dev Disabil. Apr; 2011 49(2): 103-112. [PubMed: 21446873]

19. Williamson DA, Allen HR, Martin PD, Alfonso AJ, Gerald B, Hunt A. Comparison of Digital Photography to Weighed and Visual Estimation of Portion Sizes. J Am Diet Assoc. Sep; 2003 103(9):1139-1145. [PubMed: 12963941]

20. Higgins JA, LaSalle AL, Zhaoxing P, et al. Validation of Photographic Food Records in Children: Are Pictures Really Worth a Thousand Words? Eur J Clin Nutr. Aug; 2009 63(8):1025-1033. [PubMed: 19259111] 
21. Martin CK, Han H, Coulon SM, Allen HR, Champagne CM, Anton SD. A Novel Method to Remotely Measure Food Intake of Free-Living Individuals in Real Time: The Remote Food Photography Method. Br J Nutr. Feb; 2009 101(3):446-456. [PubMed: 18616837]

22. Wang DH, Kogashiwa M, Ohta S, Kira S. Validity and Reliability of a Dietary Assessment Method: The Application of a Digital Camera with a Mobile Phone Card Attachment. J Nutr Sci Vitaminol (Tokyo). Dec; 2002 48(6):498-504. [PubMed: 12775117]

23. Swanson M. Digital Photography as a Tool to Measure School Cafeteria Consumption. J Sch Health. Aug; 2008 78(8):432-437. [PubMed: 18651930]

24. Dahl Lassen A, Poulsen S, Ernst L, Kaae Andersen K, Biltoft-Jensen A, Tetens I. Evaluation of a Digital Method to Assess Evening Meal Intake in a Free-Living Adult Population. Food Nutr Res. 2010:54.

25. Kikunaga S, Tin T, Ishibashi G, Wang DH, Kira S. The Application of a Handheld Personal Digital Assistant with Camera and Mobile Phone Card (Wellnavi) to the General Population in a Dietary Survey. J Nutr Sci Vitaminol (Tokyo). Apr; 2007 53(2):109-116. [PubMed: 17615997]

26. Lazarte C, Encinas ME, Alegre C, Granfeldt Y. Validation of Digital Photographs, as a Tool in 24H Recall, for the Improvement of Dietary Assessment among Rural Populations in Developing Countries. Nutr J. Aug 29.2012 11(1):61. [PubMed: 22931128]

27. Martin CK, Newton RL Jr, Anton SD, et al. Measurement of Children's Food Intake with Digital Photography and the Effects of Second Servings Upon Food Intake. Eat Behav. Apr; 2007 8(2): 148-156. [PubMed: 17336784]

28. Elinder LS, Brunosson A, Bergstrom H, Hagstromer M, Patterson E. Validation of Personal Digital Photography to Assess Dietary Quality among People with Intellectual Disabilities. J Intellect Disabil Res. Feb; 2012 56(2):221-226. [PubMed: 21801265]

29. Humphries K, Traci MA, Seekins T. Food on Film: Pilot Test of an Innovative Method for Recording Food Intake of Adults with Intellectual Disabilities Living in the Community. Journal of Applied Research in Intellectual Disabilities. 2008; 21(2):168-173.

30. Academy of Nutrition and Dietetics. Providing Nutrition Services for Infants, Children, and Adults with Developmental Disabilities and Special Health Care Needs. J Am Diet Assoc. Jan; 2004 104(1):97-107. [PubMed: 14702592]

31. U.S. Department of Health and Human Services. [Accessed December 21 2012] Healthy People 2020. http://www.healthypeople.gov/2020/

32. Janicki, M.; Breitenbach, N. Summative Report 2000. World Health Organization; 2000. Aging and Intellectual Disabilities: Improving Longevity and Promoting Healthy Aging.

33. Ramdoss S, Machalicek W, Rispoli M, Mulloy A, Lang R, O’Reilly M. Computer-Based Interventions to Improve Social and Emotional Skills in Individuals with Autism Spectrum Disorders: A Systematic Review. Dev Neurorehabil. 2012; 15(2):119-135. [PubMed: 22494084]

34. Blanton CA, Moshfegh AJ, Baer DJ, Kretsch MJ. The Usda Automated Multiple-Pass Method Accurately Estimates Group Total Energy and Nutrient Intake. J Nutr. Oct; 2006 136(10):25942599. [PubMed: 16988132]

35. Conway JM, Ingwersen LA, Vinyard BT, Moshfegh AJ. Effectiveness of the Us Department of Agriculture 5-Step Multiple-Pass Method in Assessing Food Intake in Obese and Nonobese Women. Am J Clin Nutr. May; 2003 77(5):1171-1178. [PubMed: 12716668]

36. Wright JD, Borrud LG, McDowell MA, Wang CY, Radimer K, Johnson CL. Nutrition Assessment in the National Health and Nutrition Examination Survey 1999-2002. J Am Diet Assoc. May; 2007 107(5):822-829. [PubMed: 17467380]

37. Nurtition Coordinating Center. Ndsr 2011 User Manual. Minneapolis, MN: University of Minnesota; 2011.

38. Schakel SF. Maintaining a Nutrient Database in a Changing Marketplace: Keeping Pace with Changing Food Products - a Research Perspective. Journal of Food Composition and Analysis. 2001; 14(3):315-322.

39. Goldstein, H. Multilevel Statistical Models. Chichester, UK: John Wiley \& Sons, Ltd; 2010.

40. Raudenbush, SW.; Bryk, AS. Hierarchical Linear Models: Applications and Data Analysis Methods. Vol. 1. Thousand Oaks, CA: SAGE Publications, Incorporated; 2002. 
41. Hox, J. Multilevel Analysis: Techniques and Applications. New York, NY: Routledge Academic; 2010.

42. Tooze JA, Kipnis V, Buckman DW, et al. A Mixed-Effects Model Approach for Estimating the Distribution of Usual Intake of Nutrients: The Nci Method. Statistics in medicine. 2010; 29(27): 2857-2868. [PubMed: 20862656]

43. Cohen, J. Statistical Power Analysis for the Behavioral Sciences. New York, NY: Routledge Academic; 1988.

44. SAS Institute. Sas/Stat 9.3 User's Guide. Cary, NC: SAS Institute Inc; 2002-2010.

45. Hill RJ, Davies PS. The Validity of Self-Reported Energy Intake as Determined Using the Doubly Labelled Water Technique. Br J Nutr. Apr; 2001 85(4):415-430. [PubMed: 11348556]

46. Subar AF, Kipnis V, Troiano RP, et al. Using Intake Biomarkers to Evaluate the Extent of Dietary Misreporting in a Large Sample of Adults: The Open Study. Am J Epidemiol. Jul 1; 2003 158(1): 1-13. [PubMed: 12835280]

47. Trabulsi J, Schoeller DA. Evaluation of Dietary Assessment Instruments against Doubly Labeled Water, a Biomarker of Habitual Energy Intake. Am J Physiol Endocrinol Metab. Nov; 2001 281(5):E891-899. [PubMed: 11595643] 


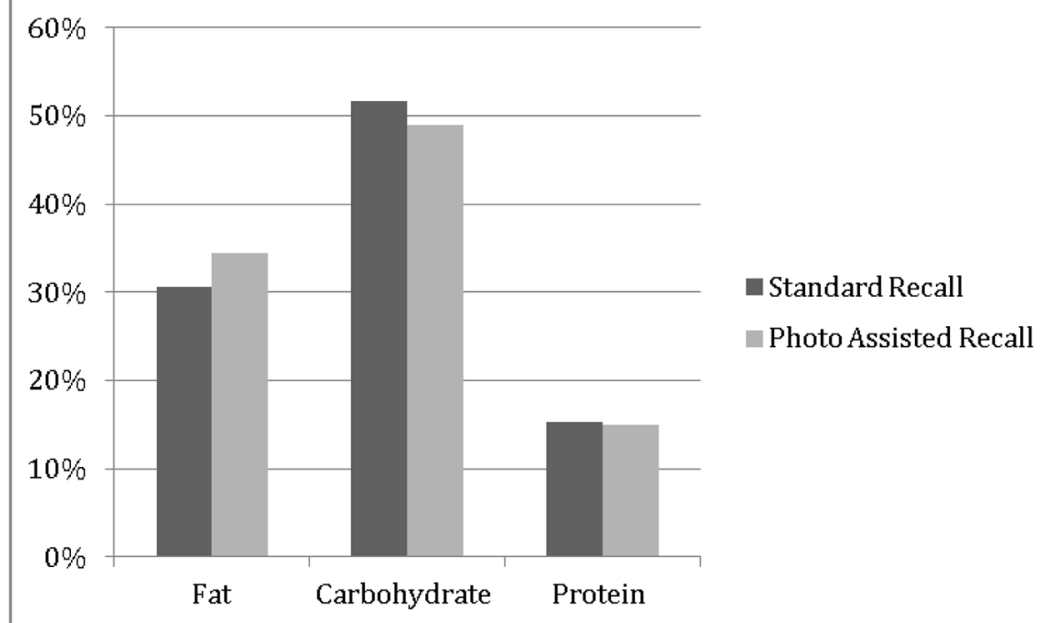

Figure 1.

Macronutrient composition as percentage of total energy for standard and photo-assisted dietary recalls per eating occasion

No statistical difference was observed; all $p>0.05$ 
Table 1

Study sample characteristics

\begin{tabular}{|c|c|c|}
\hline Variable & $n$ & $M \pm S D / \%$ \\
\hline Age (years) & 23 & $26.4 \pm 9.7$ \\
\hline \multicolumn{3}{|l|}{ Gender } \\
\hline Male & 12 & $52.2 \%$ \\
\hline Female & 11 & $47.8 \%$ \\
\hline \multicolumn{3}{|l|}{ Race } \\
\hline White & 18 & $78.3 \%$ \\
\hline Other & 5 & $21.7 \%$ \\
\hline \multicolumn{3}{|l|}{ Ethnicity } \\
\hline Not Hispanic/Latino & 23 & $100.0 \%$ \\
\hline Hispanic/Latino & 0 & $0.0 \%$ \\
\hline \multicolumn{3}{|l|}{ Education level } \\
\hline Less than 9th grade & 0 & $0.0 \%$ \\
\hline 9th-12th grade & 11 & $47.8 \%$ \\
\hline High school/GED & 9 & $39.1 \%$ \\
\hline More than high school & 3 & $13.0 \%$ \\
\hline \multicolumn{3}{|l|}{ Level of IDD impairment } \\
\hline Mild & 14 & $60.9 \%$ \\
\hline Moderate & 9 & $39.1 \%$ \\
\hline
\end{tabular}




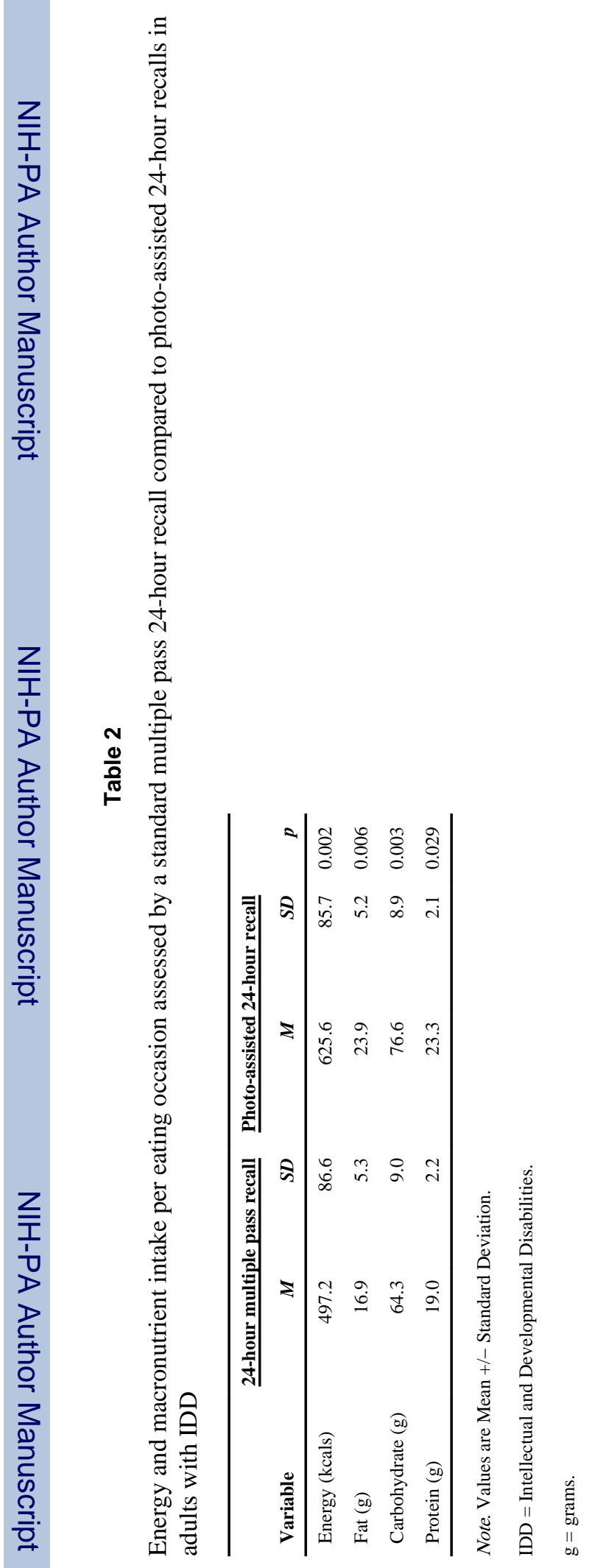

